

\title{
Examining the Influence of Mobile Store Features on User E-Satisfaction: Extending UTAUT2 with Personalization, Responsiveness, and Perceived Security and Privacy
}

Ali Abdallah Alalwan, Abdullah M. Baabdullah, Nripendra P. Rana, Yogesh

Dwivedi, Hatice Kizgin

\section{To cite this version:}

Ali Abdallah Alalwan, Abdullah M. Baabdullah, Nripendra P. Rana, Yogesh Dwivedi, Hatice Kizgin. Examining the Influence of Mobile Store Features on User E-Satisfaction: Extending UTAUT2 with Personalization, Responsiveness, and Perceived Security and Privacy. 18th Conference on e-Business, e-Services and e-Society (I3E), Sep 2019, Trondheim, Norway. pp.50-61, 10.1007/978-3-030-293741_5. hal-02510097

\author{
HAL Id: hal-02510097 \\ https://hal.inria.fr/hal-02510097
}

Submitted on 17 Mar 2020

HAL is a multi-disciplinary open access archive for the deposit and dissemination of scientific research documents, whether they are published or not. The documents may come from teaching and research institutions in France or abroad, or from public or private research centers.
L'archive ouverte pluridisciplinaire HAL, est destinée au dépôt et à la diffusion de documents scientifiques de niveau recherche, publiés ou non, émanant des établissements d'enseignement et de recherche français ou étrangers, des laboratoires publics ou privés.

\section{(c)(1)}

Distributed under a Creative Commons Attribution| 4.0 International License 


\title{
Examining the Influence of Mobile Store Features on User E-Satisfaction: Extending UTAUT2 with Personalization, Responsiveness, and Perceived Security and Privacy
}

\author{
Ali Abdallah Alalwan ${ }^{1}$, Abdullah M. Baabdullah², Nripendra P Rana ${ }^{3}$, Yogesh K \\ Dwivedi $^{4}$, Hatice Kizgin ${ }^{5}$ \\ ${ }^{1}$ Assistant professor, Amman College of Financial and Administrative Sciences, Al-Balqa \\ Applied University, Amman, Jordan \\ alwan.a.a.ali@gmail.com \\ Alwan_jo@bau.edu.jo \\ ${ }^{2}$ Assistant professor, Department of Management Information Systems, Faculty of Economics \\ and Administration, King Abdulaziz University, Jeddah, Kingdom of Saudi Arabia \\ baabdullah@kau.edu.sa \\ ${ }^{3}$ Professor of Digital Marketing and Head of International Business, Marketing and Branding \\ Research Centre, School of Management, Bradford University, Bradford, UK \\ nrananp@gmail.com \\ ${ }^{4}$ Professor of Digital Marketing and Innovation, School of Management, Swansea University \\ Bay Campus, Fabian Way, Swansea SA1 8EN, UK \\ ykdwivedi@gmail.com \\ ${ }^{5}$ Senior Lecturer in Marketing, University of Bradford, School of Management, Emm Ln, \\ Bradford BD9 4JL, UK \\ kizgin.hatice@gmail.com
}

\begin{abstract}
Despite the rapid growth in mobile stores (e.g., Apple Store, Google Play), scholarly research in this area is still in the early stages. In particular, there is a need for more empirical analysis of how the main features of these new systems shape the customer experience. This study aims to empirically identify and validate the key factors shaping users' satisfaction toward mobile stores. The conceptual model was proposed based on a group of the main factors from the extended Unified Theory of Acceptance and Use of Technology (UTAUT2), mobile interactivity, and perceived security and privacy. The empirical analysis was conducted in Jordan by collecting data from a convenience sample of users of mobile stores. Structural equation modelling was applied to test the current study's model. The results support the significant impact of performance expectancy, price value, hedonic motivation, personalization, responsiveness, and perceived security and privacy on user satisfaction. Discussion of the main limitations and future research directions are also provided.
\end{abstract}

Keywords: Mobile App Stores, UTAUT2, Mobile Interactivity, E-Satisfaction.

\section{Introduction}

The revolution in smartphone technologies and the rapidly growing number of smartphone users have led to mobile stores (e.g., Apple Store, Google Play) becoming 
increasingly important [19;35]. According to a report published by [43], Apple Store alone contains more than 2.2 million applications that can be bought and downloaded by Apple platform users, while Google's Play Store hosts more than 2.8 million applications available to other kinds of smartphone user. By the end of 2017, 178.1 billion applications had been downloaded by smartphone users [44]. The importance of mobile stores is likely to increase further, as the number of smartphone users is expected to reach 5 billion in 2019 [44]. At the same time, the high engagement with social media and other digital applications will also increase the use of mobile stores $[8 ; 9 ; 31 ; 40]$.

Prior studies [e.g. 2; 24; 18;23] indicate a number of factors (such as the level usability, attractiveness, cost, personalization, and privacy) that are frequently reported to play a considerable role in shaping user satisfaction and intention to continue using mobile stores. Capturing a comprehensive picture of users' perception and experience with these digital stores could help practitioners better design the stores so that they cover the most important aspects from the users' perspective [23; 15]. Mobile stores have rarely been addressed by researchers from the customer and digital marketing perspectives [39]. Accordingly, empirical research on and validation of the most important aspects that shape customer satisfaction toward mobile stores are needed. The present study seeks to fill this gap. Moreover, issues relating to mobile stores have not been explored for Middle Eastern and Arab countries. Therefore, in order to advance understanding of mobile use in this region of the world, this study conducts empirical research on mobile users in Jordan.

The rest of this paper is structured as follows: section 2 outlines the theoretical foundation and conceptual model; section 3 explains the research methodology adopted to conduct the empirical analysis; section 4 presents the results of structural equation modelling (SEM); section 5 discusses the main empirical results along with practical and theoretical implications; and the final section presents the main limitations of the current study and suggested future research directions.

\section{Literature Review}

Due to its novelty, there is very limited literature on the customer's perspective of using mobile stores [19]. Most studies have focused on the technical and technological characteristics of mobile stores and related issues [14; 15;23]. Chen and Liu (2011) applied an observational approach to test three main characteristics: comment, static, and dynamic. Harman et al. (2012) used an algorithm to identify the most important characteristics of mobile stores, such as price, download rank, and rate mean.

Iacob et al. (2013) manually tested the most important features of mobile stores, finding that versioning, comparative feedback, price feedback, and usability are key mobile store characteristics that shape the user's experience. Based on the same manual method adopted by [24], other important features (namely, the quality, functionality, and aesthetics) were reported by [21] for the Google Play store. Chandy and Gu (2012) examined the iOS App store using a Classification and Regression Tree and found that users pay considerable attention to the features related to number of apps, reviewing, rating mean, and ranking and rating statistics.

Among several studies that have addressed mobile stores from the user's perspective, Shen (2015) demonstrated that the association between reputation sources and users' 
attitudes toward mobile stores is significantly predicted by the role of perceived risk. Liu et al. (2014) also found that the sales volume of Google Play apps are largely predicted by the freemium strategy and the quality of the platforms. Security features (i.e., privacy protection, safe browsing, and malware prevention) were found by [32] to have a significant impact on the user's satisfaction toward the Google Play store.

Despite the contribution of such prior attempts to advance the current understanding about the important aspects of mobile stores, there has not yet been an attempt to examine mobile stores from the user's perspective. Moreover, there is a need for a solid theoretical foundation and a conceptual model that can capture the most important features from the user's perspective.

\section{Conceptual Model}

As this study concerns technology acceptance from the customer's perspective, the extended Unified Theory of Acceptance and Use of Technology (UTAUT2) was considered as the proposed conceptual model $[4 ; 5 ; 6 ; 47]$. UTAUT2 was based on the first version of Venkatesh et al.'s (2012) model and considered to be more suitable for the customer context. Furthermore, the ability of UTAUT2 to predict individuals' behaviour and reaction toward several types of technology has been widely demonstrated $[17 ; 38 ; 46]$.

Five factors from UTAUT2 - performance expectancy (PE), effort expectancy (EE), hedonic motivation (HM), price value (PV), and habit (HT) - were considered as key predictors of users' e-satisfaction (e-SATIS). Perceived privacy (PRV) and security (PS), which are critical aspects associated with mobile technology and mobile stores, were also considered in the current study model to predict users' e-satisfaction [13;20]. Mobile store technology enjoys a high degree of interactivity [28], so two dimensions of mobile interactivity - responsiveness (RSP) and personalization (PRS) - were also proposed to have a direct effect on users' satisfaction. Figure 1 presents the conceptual model.

\subsection{Performance expectancy}

Performance expectancy can be defined according to [47] as the cognitive and functional benefits captured by users of mobile stores. This construct has been largely found by prior literature on mobile technology to have an impact on customers' and users' intention and satisfaction $[4 ; 5 ; 6 ; 46]$. Therefore, users could be more satisfied with their experience with a mobile store if they perceive the store as more useful and productive for their daily life. Accordingly, the following hypothesis proposes:

H1 Performance expectancy will impact user e-satisfaction toward mobile stores.

\subsection{Effort expectancy}

Effort expectancy is related to the customers' perception that the targeted applications are easy to use and understand [3;47]. Users are more likely to be dissatisfied with their experience of using mobile stores if they feel that these stores are difficult to use. This assumption has been largely supported by prior studies that have tested applications similar to mobile technology [e.g., 10; 47]. Thus, the following hypothesis proposes: H2: Effort expectancy will impact user e-satisfaction toward mobile stores. 


\subsection{Hedonic motivation}

As argued by [47], customer experience with new systems could be affected by the role of intrinsic motivation. Mobile stores provide users with a wide range of social and entertainment apps that could accelerate customers' feelings of pleasure, and hence to contribute to the level of customers' satisfaction, as reported by studies that have tested the role of hedonic motivation [e.g., 4; 3; 8; 9]. Accordingly, the following hypothesis proposes:

H3: Hedonic motivation will impact user e-satisfaction toward mobile stores.

\subsection{Price value}

As proposed by [47], customers' satisfaction could be related to the financial cost of using new systems like mobile stores. Accordingly, customers will not be fully satisfied about their experience of using mobile stores if the perceived benefits are less than the financial costs. The role of price value has been demonstrated by a number of studies on mobile technology, such as [2] and [8]. Accordingly, the following hypothesis proposes:

H4: Price value will impact user e-satisfaction toward mobile stores.

\subsection{Habit}

Venkatesh et al. (2012, p.161) defined habit as "the extent to which people tend to perform behaviour automatically because of learning." Users seem to be highly attached to their smartphones and spend a considerable amount of time using and browsing mobile stores and downloading apps. They are more likely to have a habitual behaviour and accumulative knowledge and experience in using these apps. This, in turn, could positively impact on their experience of using mobile stores. Thus, the following hypothesis proposes:

H5: Habit will impact user e-satisfaction toward mobile stores.

\subsection{Responsiveness}

Perceived responsiveness captures how regularly and quickly users' questions and requests are addressed [49]. Furthermore, responsiveness can be viewed as the extent to which mobile stores provide users with relevant and pertinent information and responses to user questions and needs [25]. Therefore, it can be argued that the level of users' satisfaction is likely to be improved by increasing the level of responsiveness. Thus, the following hypothesis proposes:

H6: Responsiveness will impact user e-satisfaction toward mobile stores.

\subsection{Personalization}

Mobile technology, especially that related to smartphones, enjoys a high level of personalization that enriches the user's experience. Users of mobile technologies (e.g., mobile stores, mobile shopping) are more likely to be happy about their experience if more products, services, information, and applications are customized and tailored to their needs and requirements $[1 ; 34 ; 35]$. Accordingly, the level of users' satisfaction is likely to be increased by improving the level of personalization in mobile stores [28]; [36]; [37]; and [30]. Thus, the following hypothesis proposes:

H7: Personalization will impact user e-satisfaction toward mobile stores. 


\subsection{Perceived privacy}

Perceived privacy is defined as the "user's perceptions about the protection of all the data that is collected (with or without users being aware of it) during users' interactions with an Internet banking system" [48]. Practically, to use mobile stores properly, users are requested to disclose their personal and financial information. Therefore, a level of perceived privacy is likely to motivate the usage of mobile stores and to enhance the level of users' satisfaction with their experience of mobile stores. Thus, the following hypothesis proposes:

H8: Perceived privacy will impact user e-satisfaction toward mobile stores.

\subsection{Perceived security}

Perceived security can be articulated as "the extent to which a consumer believes that making payments online is secure" (Vijayasarathy, 2004, p. 748). The extent of protection and security in using mobile stores plays an important role not only in increasing users' intention to use such platforms but also in their satisfaction with these digital stores. Thus, the following hypothesis proposes:

H9: Perceived security will impact user e-satisfaction toward mobile stores.



Figure 1: Conceptual model [adapted from $13 ; 27 ; 28 ; 47]$

\section{Research Methodology}

The empirical part of the current study was conducted in Jordan from November 2018 to the end of January 2019. It involved collecting data from 500 Jordanian users of mobile stores (Apple Store and Google Play). A self-administered questionnaire was developed and allocated to the targeted participants $[11 ; 16]$. The main model 
constructs were measured using well-validated scale items from prior literature. For example, all items from the UTAUT2 framework were adopted from [47], while the items of responsiveness and personalization were extracted from [26]. Perceived privacy and security were extracted from the scale used by [27], and e-satisfaction was tested using items derived from [7]. By using the back translation method suggested by [12], all items were translated into Arabic, the main language in Jordan. To ensure an adequate level of reliability, prior to the main survey a pilot study was conducted with a small sample of 25 users of mobile stores. Cronbach's alpha values for all constructs were above their recommended level of 0.70 [33].

\section{Results}

A two-stage SEM method was used to test the current study's model. The two-stage method has been widely used by a many high-impact journal papers, and it was considered to be more suitable for testing the goodness of fit and validating the constructs of the current study's model, as well as for testing the main research hypotheses [22].

In the first stage, the results of the SEM measurement model largely supported the level of goodness of fit. All of the fit indices had values within their suggested level, that is, goodness-of-fit index $(\mathrm{GFI})=0.901$; adjusted goodness-of-fit index $(\mathrm{AGFI})=0.845$; comparative fit index $(\mathrm{CFI})=0.965$; normed chi-square $(\mathrm{CMIN} / \mathrm{DF})=2.325$; normed-fit index $(\mathrm{NFI})=0.932$; and root mean square error of approximation $(\mathrm{RMSEA})=0.053$ [Byrne, 2010; 22; 45]. Likewise, all model constructs were found to have adequate values of composite reliability $(\mathrm{CR})(>0.70)$ and average variance extracted (AVE) (>0.50).More specifically: $\mathrm{PE}(\mathrm{CR}=0.912 ; \mathrm{AVE}=0.721) ; \mathrm{EE}(\mathrm{CR}=0.933 ; \mathrm{AVE}=0.777)$; RSP (CR=0.984; AVE=0.953); PV (CR=0.866; AVE=0.685); PS (CR=0.903; $\mathrm{AVE}=0.705)$; PRV (CR=0.838; AVE=0.635); E-SATIS (CR=0.943; AVE=0.847); HM $(\mathrm{CR}=0.838 ; \mathrm{AVE}=0.622)$; $\mathrm{PRS}(\mathrm{CR}=0.778 ; 0.539) ; \mathrm{HT}(\mathrm{CR}=0.971 ; \mathrm{AVE}=0.919)$.

The structural model results indicated that the model was able to predict about 0.54 of variance in user satisfaction (see Figure 2). The model also adequately fit the observed data as all of its fit indices were found within their threshold values (CMIN/DF=2.451; $\mathrm{GFI}=0.90 ; \mathrm{AGFI}=0.832 ; \mathrm{CFI}=0.952 ; \mathrm{NFI}=0.921 ; \mathrm{RMSEA}=0.0601)$. Of the nine hypotheses, seven were confirmed. Figure 2 shows that the most significant factor predicting e-satisfaction was PE $(\gamma=0.49, \mathrm{p}<0.000)$, followed by PRS $(\gamma=0.32$, $\mathrm{p}<0.000)$, and then PRV $(\gamma=0.29, \mathrm{p}<0.000)$. PS was the fourth factor to significantly contribute to E-SATIS $(\gamma=0.20, \mathrm{p}<0.000)$. E-SATIS was also noticed to be significantly predicted by the role of RSP $(\gamma=0.19, \mathrm{p}<0.000)$, PV $(\gamma=0.14, \mathrm{p}<0.003)$, and HM $(\gamma=0.18, \mathrm{p}<0.000)$. On the other hand, neither EE $(\gamma=-0.02, \mathrm{p}<0.775)$ nor HT $(\gamma=-0.01$, $\mathrm{p}<0.877$ ) have a significant relationship with e-satisfaction. 


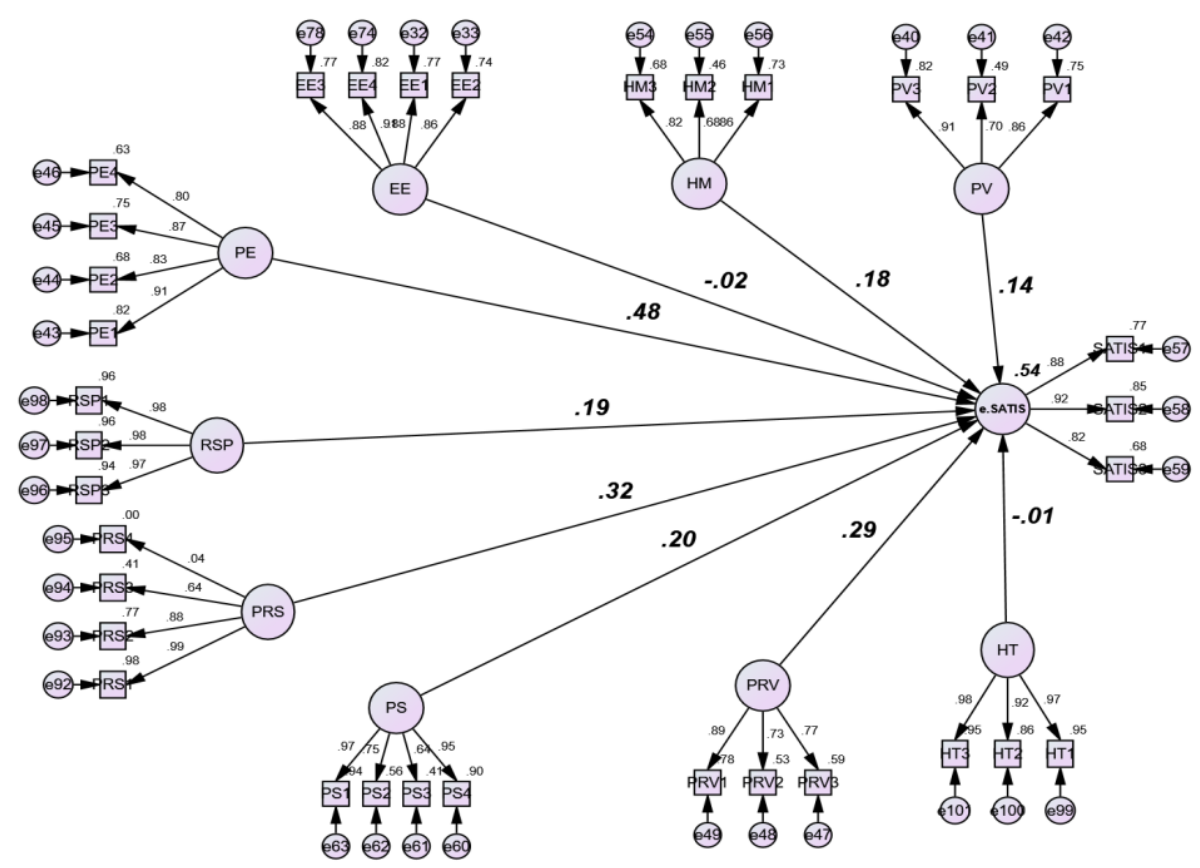

Figure 2: Validation of the conceptual model

\section{Discussion}

This study aimed to capture an accurate picture of the main factors that could shape users' satisfaction toward mobile stores. The empirical results supported the proposed conceptual model, which was able to capture an adequate level of predictive validity with 0.54 of variance accounted in e-satisfaction. In addition, the model satisfactorily meets the criteria pertaining to model fitness.

The path coefficient analyses show that seven factors - PE, PRS, PRV, PS, RSP, HM, and PV - significantly contribute to E-SATIS. According to Figure 2, the most powerful factor contributing to E-SATIS is PE. These results indicate that Jordanian users are drawn to and motivated by the level of utilitarian value in mobile stores. This could be because of the ability of these digital stores to help users find and download the requested apps using less time and effort. Moreover, it is likely that, because of the large number of useful apps available on these platforms, mobile stores are considered by users to be really useful and productive in their everyday lives.

As mobile stores require users to disclose and provide their own personal and financial information, both perceived privacy and security were the focus of attention of the participants in the current study. It is noticeable that users' satisfaction is largely shaped and predicted by the level of privacy and security in using mobile stores, which has been largely supported by prior mobile technology studies [e.g., 10; 27; 40; 41].

Satisfaction was also noticed to be increased among those users who perceive mobile stores to have a high degree of personalization. In research on digital marketing, it has been commonly argued and shown that customization is a key leverage of users' experience and satisfaction. The innovative features of mobile stores allow users to 
have a high level of customized buying experience, which in turn enriches the level of users' satisfaction. Users were also found to pay attention to the extent of responsiveness in mobile stores. This indicates that as long as users find a high level of correspondence between their needs, preferences, and lifestyles, and what is available in mobile stores, they will be more satisfied about their experience of using such digital platforms [9].

By the same token, users were found to pay a considerable attention to whether mobile stores are reasonably priced. To put this differently, users are more likely to be satisfied about their experience of using mobile stores if they see more monetary value from this experience. This was also demonstrated for Jordanian mobile banking users in a study conducted by [4]. The results of the current study also support the role of hedonic motivation in shaping users' satisfaction. This indicates that a high level of entertainment in the users' experience of mobile stores leads to a high level of satisfaction. This might be related to the degree of novelty that mobile stores enjoy. As mentioned above, mobile stores have high levels of personalization and responsiveness, which in turn contributes to the level of intrinsic utility.

\subsection{Research contribution}

First, the significance of this study comes from the importance of mobile stores as a new technology requiring further research and analysis. Secondly, the topic of mobile stores has rarely been addressed from the user's perspective. Moreover, the vast majority of these limited studies have not adopted a systematic approach in proposing their models. Furthermore, there is as yet no study that has explored the subject of mobile stores in relation to Jordan. Accordingly, this study makes a number of theoretical contributions at different levels. It provides an accurate picture of the main factors that can shape user satisfaction toward mobile stores. The current model was developed and empirically validated, so it can be used in different contexts and countries to investigate how users perceive and use mobile stores differently.

\section{Limitations and Future Research Directions}

There are a number of limitations in the current study that could be addressed in future studies. Due to the word count restrictions, a limited and very short discussion has been provided. Accordingly, the hypotheses could be discussed in more detail in future studies. Although this study covers important aspects that could shape the user's satisfaction toward mobile stores, there are still other factors worth considering in future research. For instance, only two aspects of mobile interactivity (personalization and responsiveness) were tested in the current study, while other aspects (active control, ubiquitous connectivity, connectedness, and synchronicity) were ignored. Researchers interested in the area of mobile stores might consider these other factors. The technical features of mobile phone (e.g., phone brand and type, size of screen, battery capacity, memory) could also be considered by future studies as they have not been covered in the current study. This study has tested mobile stores in general, but it does not address the differences between Apple Store and Google Play. It would be worth conducting a comparison between these mobile stores to see how users' experiences and reactions are different from one store to another. Finally, the current study was purely quantitative, so a qualitative study could provide further and deeper understanding of the main factors that shape users' experience and satisfaction with mobile stores. 


\section{References}

1. Alalwan, A. A. (2018). Investigating the impact of social media advertising features on customer purchase intention. International Journal of Information Management, 42, 65-77.

2. Alalwan, A. A. (2020). Mobile food ordering apps: An empirical study of the factors affecting customer e-satisfaction and continued intention to reuse. International Journal of Information Management, 50, $28-44$.

3. Alalwan, A. A., Baabdullah, A. M., Rana, N. P., Tamilmani, K., \& Dwivedi, Y. K. (2018). Examining adoption of mobile internet in Saudi Arabia: Extending TAM with perceived enjoyment, innovativeness and trust. Technology in Society, 55, 100-110.

4. Alalwan, A. A., Dwivedi, Y. K., \& Rana, N. P. (2017). Factors influencing adoption of mobile banking by Jordanian bank customers: Extending UTAUT2 with trust. International Journal of Information Management, $37(3), 99-110$.

5. Alalwan, A. A., Dwivedi, Y. K., Rana, N. P., \& Algharabat, R. (2018). Examining factors influencing Jordanian customers' intentions and adoption of internet banking: Extending UTAUT2 with risk. Journal of Retailing and Consumer Services, 40, 125-138.

6. Alalwan, A. A., Dwivedi, Y. K., Rana, N. P., \& Williams, M. D. (2016). Consumer adoption of mobile banking in Jordan: Examining the role of usefulness, ease of use, perceived risk and self-efficacy. Journal of Enterprise Information Management, 29(1), 118-139.

7. Anderson, E. W., \& Sullivan, M. W. (1993). The antecedents and consequences of customer satisfaction for firms. Marketing Science, 12(2), 125-143.

8. Baabdullah, A. M. (2018a). Consumer adoption of Mobile Social Network Games (M-SNGs) in Saudi Arabia: The role of social influence, hedonic motivation and trust. Technology in Society, 53, 91-102.

9. Baabdullah, A. M. (2018b). Factors influencing adoption of mobile social network games (M-SNGs): The role of awareness. Information Systems Frontiers, 1-17.

10. Baabdullah, A. M., Alalwan, A. A., Rana, N. P., Patil, P., \& Dwivedi, Y. K. (2019). An integrated model for m-banking adoption in Saudi Arabia. International Journal of Bank Marketing, 37 (2), 452-478.

11. Bhattacherjee, A. (2012). Social science research: Principles, methods, and practices. (2nd Ed.). Florida, USA: AnolBhattacherjee.

12. Brislin, R. (1976). Comparative research methodology: Cross-cultural studies. International Journal of Psychology, 11(3), 215-229.

13. Casaló, L. V., Flavián, C., \& Guinalíu, M. (2007). The role of security, privacy, usability and reputation in the development of online banking. Online Information Review, 31(5), 583-603.

14. Chandy, R., \& Gu, H. (2012). Identifying spam in the iOS app store. In Proceedings of the 2nd Joint WICOW/AIRWeb Workshop on Web Quality (pp. 56-59). ACM. 
15. Chen, M., \& Liu, X. (2011, February). Predicting popularity of online distributed applications: iTunes app store case analysis. In Proceedings of the 2011 iConference (pp. 661-663). ACM.

16. Dwivedi, Y. K., Choudrie, J., \& Brinkman, W. P. (2006). Development of a survey instrument to examine consumer adoption of broadband. Industrial Management and Data Systems, 106(5), 700-718.

17. Dwivedi, Y. K., Rana, N. P., Jeyaraj, A., Clement, M., \& Williams, M. D. (2017). Re-examining the unified theory of acceptance and use of technology (UTAUT): Towards a revised theoretical model. Information Systems Frontiers, 1-16. DOI:10.1007/s10796-017-9774-y

18. Fu, B., Lin, J., Li, L., Faloutsos, C., Hong, J., \& Sadeh, N. (2013). Why people hate your app: Making sense of user feedback in a mobile app store. In Proceedings of the 19th ACM SIGKDD International Conference on Knowledge Discovery and Data mining (pp. 1276-1284). ACM.

19. Genc-Nayebi, N., \& Abran, A. (2017). A systematic literature review: Opinion mining studies from mobile app store user reviews. Journal of Systems and Software, 125, 207-219.

20. Gutierrez, A., O’Leary, S., Rana, N. P., Dwivedi, Y. K., \& Calle, T. (2018). Using privacy calculus theory to explore entrepreneurial directions in mobile location-based advertising: Identifying intrusiveness as the critical risk factor. Computers in Human Behavior, 95, 295-306.

21. Ha, E., \& Wagner, D. (2013). Do Android users write about electric sheep? Examining consumer reviews in google play. In 2013 IEEE 10th Consumer Communications and Networking Conference (CCNC) (pp. 149-157). IEEE.

22. Hair Jr., J. F., Black, W. C., Babin, B. J., \& Anderson, R. E. (2010). Multivariate data analysis: A global perspective. (7th Ed.). Upper Saddle River, NJ: Pearson Education International.

23. Harman, M., Jia, Y., \& Zhang, Y. (2012). App store mining and analysis: MSR for app stores. In Proceedings of the 9th IEEE Working Conference on Mining Software Repositories (pp. 108-111). IEEE Press.

24. Iacob, C., Veerappa, V., \& Harrison, R. (2013). What are you complaining about? A study of online reviews of mobile applications. In Proceedings of the 27th International BCS Human Computer Interaction Conference (p. 29). British Computer Society.

25. Johnson, G. J., Bruner II, G. C., \& Kumar, A. (2006). Interactivity and its facets revisited: Theory and empirical test. Journal of Advertising, 35(4), 35-52.

26. Kim, A. J., \& Ko, E. (2012). Do social media marketing activities enhance customer equity? An empirical study of luxury fashion brand. Journal of Business research, 65(10), 1480-1486.

27. Kim, K. J., Jeong, I. J., Park, J. C., Park, Y. J., Kim, C. G., \& Kim, T. H. (2007). The impact of network service performance on customer satisfaction and loyalty: High-speed internet service case in Korea. Expert Systems with Applications: An International Journal, 32(3), 822-831.

28. Lee, T. (2005). The impact of perceptions of interactivity on customer trust and transaction intentions in mobile commerce. Journal of Electronic Commerce Research, 6(3), 165-180. 
29. Liu, C. Z., Au, Y. A., \& Choi, H. S. (2014). Effects of freemium strategy in the mobile app market: An empirical study of google play. Journal of Management Information Systems, 31(3), 326-354.

30. Liu, Y. (2003). Developing a scale to measure the interactivity of websites. Journal of Advertising Research, 43(2), 207-216.

31. Marriott, H. R., Williams, M. D., \& Dwivedi, Y. K. (2017). What do we know about consumer m-shopping behaviour? International Journal of Retail and Distribution Management, 45(6), 568-586.

32. Mei-Ling, Y. A. O., Chuang, M. C., \& Chun-Cheng, H. S. U. (2018). The Kano model analysis of features for mobile security applications. Computers \& Security.

33. Nunnally, J. C., Bernstein, I. H., \& Berge, J. M. T. (1967). Psychometric Theory. New York: McGraw-Hill.

34. Pappas, I. O. (2018). User experience in personalized online shopping: a fuzzy-set analysis. European Journal of Marketing, 52(7/8), 1679-1703.

35. Pappas, I. O., Kourouthanassis, P. E., Giannakos, M. N., \& Chrissikopoulos, V. (2016). Explaining online shopping behavior with fsQCA: The role of cognitive and affective perceptions. Journal of Business Research, 69(2), 794-803.

36. Pappas, I. O., Kourouthanassis, P. E., Giannakos, M. N., \& Chrissikopoulos, V. (2017). Sense and sensibility in personalized e- commerce: How emotions rebalance the purchase intentions of persuaded customers. Psychology \& Marketing, 34(10), 972986.

37. Pappas, I.O., Pateli, A.G., Giannakos, M.N, \& Chrissikopoulos, V. (2014). Moderating effects of online shopping experience on customer satisfaction and repurchase intentions. International Journal of Retail \& Distribution Management, 42(3), 187204.

38. Rana, N. P., Dwivedi, Y. K., Lal, B., Williams, M. D., \& Clement, M. (2017). Citizens' adoption of an electronic government system: Towards a unified view. Information Systems Frontiers, 19(3), 549-568.

39. Roma, P., \& Ragaglia, D. (2016). Revenue models, in-app purchase, and the app performance: Evidence from Apple's App Store and Google Play. Electronic Commerce Research and Applications, 17, 173-190.

40. Shareef, M. A., Baabdullah, A., Dutta, S., Kumar, V., \& Dwivedi, Y. K. (2018). Consumer adoption of mobile banking services: An empirical examination of factors according to adoption stages. Journal of Retailing and Consumer Services, 43, 54-67.

41. Shareef, M. A., Dwivedi, Y. K., Stamati, T., \& Williams, M. D. (2014). SQ mGov: A comprehensive service-quality paradigm for mobile government. Information Systems Management, 31(2), 126-142.

42. Shen, G. C. C. (2015). Users' adoption of mobile applications: Product type and message framing's moderating effect. Journal of Business Research, 68(11), 2317-2321.

43. Statista. (2018a). Mobile app usage: Statistics and Facts. Available from: https://www.statista.com/topics/1002/mobile-app-usage/ Accessed 15 December 2018.

44. Statista. (2018b). Number of mobile app downloads worldwide in 2017, 2018 and 2022 (in billions). Available from: https://www.statista.com/statistics/271644/worldwide-free-and-paid-mobileapp-store-downloads/ Accessed 15 December 2018. 
45. Tabachnick, B. G., Fidell, L. S., \& Ullman, J. B. (2007). Using Multivariate Statistics. Boston, MA: Pearson.

46. Tamilmani, K., Rana, N. P., Prakasam, N., \& Dwivedi, Y. K. (2019). The battle of Brain vs. Heart: A literature review and meta-analysis of "hedonic motivation" use in UTAUT2. International Journal of Information Management, 46, 222-235.

47. Venkatesh, V., Thong, J. Y., \& Xu, X. (2012). Consumer acceptance and use of information technology: Extending the unified theory of acceptance and use of technology. MIS Quarterly, 36(1), 157-178.

48. Wang, Y.S., Wang, Y.M., Lin, H.H. and Tang, T.I. (2003), "Determinants of user acceptance of Internet banking: an empirical study", International Journal of Service Industry Management, Vol. 14 No. 5, pp. 501-519.

49. Zhao, L., \& Lu, Y. (2012). Enhancing perceived interactivity through network externalities: An empirical study on micro-blogging service satisfaction and continuance intention. Decision Support Systems, 53(4), 825-834. 